\title{
A produção de práticas de normalização nos discursos orientadores/reguladores do Atendimento Educacional Especializado
}

\author{
Eliana Pereira de Menezes* \\ Vanessa Shceid Santanna de Mello**
}

\section{Resumo}

Nas últimas décadas, temos visto o acento em ações políticas que preveem a inclusão de alunos com deficiência nas escolas regulares. Narrada como uma possibilidade de superação da situação de exclusão a que esses alunos foram "submetidos" durante anos, a escola inclusiva, "aberta à diversidade", é convocada a prever açôes e projetos para atender à nova demanda de alunos. Dentre essas açôes, localizamos o Atendimento Educacional Especializado (AEE) como um dos principais alvos de investimento do atual governo brasileiro. Esta pesquisa propõe-se a analisar as orientações para estruturaçáo do AEE nas escolas regulares, problematizando seus princípios e seus possíveis efeitos nas práticas escolares. Pelas análises empreendidas, parece-nos que a escola inclusiva deve constituir-se a partir de um questionável reconhecimento da diferença, uma vez que, segundo os discursos orientadores e reguladores produzidos pelo Governo Federal, é a escola que deve encarregar-se de delimitar as diferenças de que se fala e as açôes que devem ser empreendidas para que se possa conduzir melhor a conduta dos alunos incluídos, visando à sua normalização.

Palavras-chave: Inclusão; AEE; Normalização.

\footnotetext{
* Professora Doutora da Universidade Federal de Santa Maria (UFSM). Santa Maria, Rio Grande do Sul, Brasil

** Professora da rede de ensino de São Leopoldo e do Curso de Especialização em Educação Inclusiva da Universidade do Vale do Rio dos Sinos (UNISINOS). Sáo Leopoldo, Rio Grande do Sul, Brasil.
} 


\section{The Production of Normalizing Practices in Guiding/ Regulating Discourses of Specialized Educational Assistance}

Over the last decades, there has been an emphasis on political actions addressing the inclusion of disabled students in regular schools. Regarded as a possibility of overcoming the exclusion condition to which such students have been "subject" over time, the inclusive school, "open to diversity", has been invited to approach actions and projects to meet the new student demand. Among such actions, the Specialized Educational Assistance (SEA) has been one of the main targets of investment by the current Brazilian government. This research aims at analyzing the guidelines for structuring SEA in regular schools by problematizing their principles and possible effects on school practices. From the analyses, it seems that the inclusive school should be constituted from a questionable acknowledgement of difference. According to guiding and regulating discourses produced by the Federal Government, the school should be in charge of delimitating the differences that have been talked about and the actions that must be taken in order to better conduct the conduct of included students aiming at their normalization.

Keywords: Inclusion; Specialized Educational Assistance; Normalization.

\section{A emergência das políticas de inclusão escolar e os novos contornos impressos na educação especial}

\footnotetext{
Para começar, duas provocaçôes: assim como as ações inclusivas não são, em si mesmas, nem boas, nem corretas, nem defensáveis, as políticas de inclusão não são, por si só, nem boas nem necessárias... E isso é assim por várias razões. Em primeiro lugar, no mundo social não faz sentido pensar e falar sobre alguma coisa "por si só", falar em uma ação "em si mesma". [...] As coisas, nossas açóes e o que pensamos sobre tudo isso só fazem sentido nas relaçôes que mantêm entre si e como resto do mundo. [...] Em segundo lugar, não se pode dizer que algo é bom ou ruim, necessário ou desnecessário, sem examinar as condiçóes a partir das quais tanto se está falando acerca desse "algo", quanto se está emitindo algum julgamento sobre ele. Por isso mesmo e em terceiro lugar [...] quando falo sobre algo, sobre alguma coisa ou alguma ação, nunca me interessa partir de algum juízo de valor antecipado. Com uma antecipaçáo desse tipo, colocam-se as soluçóes antes de colocar os problemas; é como se fôssemos a campo para descobrir o que já se sabe. Além disso, corre-se sempre o risco de não se pensar de outra maneira, de não se conseguir enxergar alternativas plausíveis. (VEIGA-NETO, 2008, p. 11, grifo do autor)
} 
Ao trazer as palavras de Veiga-Neto, queremos mostrar, logo de início, que a primeira intenção desta discussão é pôr em movimento o exercício do pensamento. Sem antecipaçôes nem respostas evidentes, procuramos olhar para a educação inclusiva, buscando compreender os deslocamentos produzidos nas práticas escolares e os novos contornos impressos na educação especial na contemporaneidade. Isso se dá principalmente pelo fato de olharmos para essas questóes a partir de teóricos que empreendem estudos em uma perspectiva pós-estruturalista. Referimo-nos à leitura de autores que nos fazem exercitar a suspeita de verdades instituídas que, ao seduzirem a todos, se tornam naturalizadas.

Nessa lógica, neste primeiro momento da discussão, procuramos localizar as políticas educacionais do país, mostrando o deslocamento das açôes desenvolvidas pela educação especial com relaçâo aos alunos com deficiência e o encaminhamento desses alunos para a escola inclusiva há pelo menos mais de uma década. Ao traçar tal discussão, não pretendemos exercer a defesa da escola que pretende acolher a todos, tampouco empreender uma crítica e apontar falhas em tal processo. Pretendemos, sim, mediante análise de alguns documentos oficiais, compreender como se deu o aumento do acento inclusivo nas questôes relativas à educação no Brasil e quais os possíveis efeitos operados por essa política nas práticas escolares.

Temos visto no país, principalmente a partir da última década do século XX, a produção de políticas educacionais que preveem o acesso dos alunos com deficiência às escolas regulares. Se até então as orientaçôes previam a existência de espaços, saberes e profissionais específicos para a aprendizagem dos alunos com deficiência, em meados da década de 90, do século passado, passamos a conviver com outros discursos, que previam o encaminhamento desses alunos para a escola, nomeada também de inclusiva. Campanhas governamentais baseadas em estatísticas, pesquisas acadêmicas e ações da mídia, entre outros mecanismos, foram postos em funcionamento para operar o convencimento de todos sobre a necessidade de transformação da escola em um espaço aberto à "diferença". Nessa escola, a educação especial, antes vista como única forma de desenvolvimento das aprendizagens dos alunos com deficiência, ganha uma nova função e passa a ser nomeada como parceira. Diante dessa reconfiguração dos espaços educacionais, dá-se também a necessidade de reconfiguração dos papéis dos professores, do envolvimento das famílias e do comportamento dos próprios alunos (sejam os ditos incluídos ou não).

Apesar de o acento na inclusão surgir a partir dos anos 90 no Brasil, consideramos que, embora em caráter de orientação e não de obrigatoriedade, a primeira lei nacional que aponta como aconselhável a educação de pessoas com deficiência na rede regular é a versão da Lei de Diretrizes e Bases da Educação, no 4.024/61, segundo a qual "a educação de excepcionais deve, no que for possível, enquadrar-se no sistema geral de educação, a fim de integrá-los na comunidade” (Art. 88).

$\mathrm{Na}$ leitura desse artigo, Carvalho (2002) aponta dois aspectos para análise. O primeiro diz respeito à garantia da educação dos alunos excepcionais, que deveria ser enquadrada no sistema geral de educação e que estava condicionada pela expressão "no que for possível". Não está preciso na Lei se a condicionalidade seria determinada 
pelas condiçóes individuais de cada aluno de frequentar ou não a escola ou se seria determinada pela condiçáo do sistema de educação de absorver ou não esse aluno. Podemos nos perguntar a quem cabe (e a partir de quais critérios) determinar tal condição; entretanto, pensamos que o aspecto que merece destaque, neste texto, reside no fato de que, já na década de 60, do século passado, se falava em formas de garantir a integração e o convívio desses alunos com a comunidade.

Foi possível ver, a partir desse momento, uma ênfase nos discursos a favor da "superação" da condição de segregação social à qual os sujeitos com deficiências eram "submetidos" até então e a busca por práticas que visassem à sua inclusão. Então, questionamos: por que passa a ser interessante aproximar sujeitos com deficiência e sujeitos sem deficiência e possibilitar o convívio entre eles? Entendemos que podemos visualizar aqui uma das condiçóes que permitiram a emergência de práticas que buscam responsabilizar o maior número possível de sujeitos com relação à condução das condutas das pessoas com deficiência. Assim, "pela aproximaçáo da normalidade com a anormalidade, visualiza-se uma possibilidade maior de manutenção do olhar atento" exercido por alguns sujeitos (autorizados a isso) sobre outros (MENEZES; RECH, 2009, s/n).

Segundo Menezes e Rech (2009), o Estado, que opera sob a lógica da governamentalidade - estado permanente de governamento ${ }^{1}$ dos outros e de si mesmo - desde o século XVIII, encontra nesse momento condiçóes que possibilitam a reconfiguração das práticas de reclusão para que a condução das condutas das pessoas com deficiência se dê da maneira mais econômica e mais abrangente possível. Com isso, a inserção desses alunos nas escolas pode resultar na diminuição dos esforços do Estado no seu governamento. Na escola dita inclusiva, cada sujeito (aluno, professor, família) que nela atua é responsabilizado pelo bom desempenho do aluno com deficiência, e todos precisam ocupar-se de seu desenvolvimento, além dele mesmo.

Nessa perspectiva, no Brasil da década de 90, do século XX, somos apresentados a uma nova (e atual) Lei de Diretrizes e Bases da Educação Nacional (LDBEN), $n^{\circ}$ 9.394/96, que inclui um título inteiro (Título V) para a orientação sobre as açóes a serem desenvolvidas com relação à educação dos sujeitos com deficiência. Enfatizando ainda mais a necessidade de aproximação e convivência, a referida LDB revê o conceito de educaçáo especial, ressaltando que se trata de uma modalidade de educação ofertada aos alunos com deficiência, preferencialmente, na escola regular, e destaca o compromisso do poder público em ampliar as açóes inclusivas no país.

Parágrafo único. O Poder Público adotará, como alternativa preferencial, a ampliação do atendimento aos educandos com necessidades especiais na própria rede pública regular de ensino, independentemente do apoio às instituiçốes previstas neste artigo.

A partir da publicação dessa LDB, vimos uma série de outros documentos legais que procuram prever condiçóes de oferta de serviços que colaborem com a efetivação da escola inclusiva. São diretrizes educacionais que preveem, entre outras açôes, desde a formação do professor e formas de financiamento até a organização 
dos serviços da educação especial na escola regular e a reorganização dos espaços específicos de atendimento em educação especial destinados agora aos alunos incluídos, o que acaba colaborando para a produção da inclusão como uma prática obrigatória (não mais preferencial) e não-negociável.

A obrigatoriedade da efetivação (cada vez mais crescente) ${ }^{2}$ de matrículas dos alunos com deficiência nas escolas regulares pode ser localizada na esteira das mudanças necessárias, impostas para a produção de subjetividades adequadas às formas de vida que o mundo contemporâneo tem apresentado. Com o crescimento e a evolução das sociedades, especialmente no final do século XX, instaura-se uma nova configuração nas relaçôes entre os países, uma configuração em rede, que chamamos de globalização. Nessa configuração, cujos princípios neoliberais de mercado se disseminam nas mais variadas instâncias sociais, $\mathrm{o}$ acesso é facilitado, a oferta e a concorrência são potencializadas e, se há oferta, é preciso que haja necessidade e desejo de consumo. Para responder a essa demanda de produção dos países, faz-se preciso, que diariamente, novas necessidades sejam inventadas, necessidades essas que são cada vez mais instantâneas e que, por isso, se diferenciam das necessidades duradouras e satisfeitas em longo prazo da governamentalidade liberal. Conforme Saraiva $(2009$, s/n), na governamentalidade liberal, "haveria uma primazia para a produção de sujeitos capazes de submeterem-se ao trabalho fabril, com suas rotinas, e de sacrificarem seus desejos presentes por uma recompensa futura".

$\mathrm{Na}$ lógica da concorrência do mercado neoliberal, precisamos de sujeitosclientes permanentemente insatisfeitos e, portanto, em permanente busca de satisfação. A governamentalidade neoliberal prima pela produção de sujeitos capazes de aprender a desenvolver competências que lhes permitam participar ativamente do jogo do mercado. Assim, são apresentados novos objetivos e desafios aos espaços privilegiados para a produção de subjetividades (entre eles, a escola).

Nesse contexto, o que temos visto nos últimos anos é o esvaziamento dos espaços especiais, que durante décadas abrigaram os alunos com deficiência, e a dilatação das escolas comuns, que passaram a ocupar-se desse grupo. Temos hoje, em decorrência da política de educação inclusiva, discursos cada vez mais contundentes na direção de que todos devem estar na escola regular/inclusiva. Nessa escola de todos, práticas são desenvolvidas para que se produzam sujeitos com mínimas condiçóes de autogestão que concordem em ser conduzidos de forma a alcançar acesso e participação na sociedade.

\section{O AEE e a classificação dos alunos: práticas de normalização postas em funcionamento}

Tendo visto a emergência da inclusão como um imperativo da racionalidade neoliberal e a acentuada proliferação de discursos que produzem a necessidade da abertura da escola para todos, o que pretendemos, nesta segunda seção do trabalho, é, a partir de algumas recorrências discursivas, mostrar como a escola inclusiva, com a reorganização dos serviços da educação especial no seu interior, trabalha de forma cada vez mais consistente pela classificação dos alunos, agrupados por "categorias de 
deficiências". A depender da categoria de deficiência, diferentes estratégias de governamento são postas em funcionamento na sala de aula e no atendimento da educação especial para que se possa melhor conduzir a conduta dos alunos incluídos, visando à sua normalização. Nessa lógica, a norma, além de ter como fim classificar, ordenar e posicionar os sujeitos na sociedade, funciona na operacionalização de outros mecanismos que objetivam fazer com que cada sujeito esteja sempre em atividade no tecido social para que se mantenha no mercado.

No movimento de provisão de diretrizes para a efetivação das práticas de inclusão escolar, instaurado no Brasil oficialmente pela LDB 9.394/96, temos, a cada governo, a aprovação de políticas cada vez mais enfáticas com relação aos serviços que precisam ser desenvolvidos para que todos estejam na escola. Esta pesquisa traz para análise e discussão teórica dois documentos recentemente apresentados pelo Governo Federal que atualmente indicam o que as escolas precisam prever para a operacionalização do atendimento educacional de alunos com deficiência nos espaços educacionais, sejam eles de educação básica e/ou superior. Referimo-nos ao Decreto No 7.611, de 17 de novembro de $2011^{3}$, que dispóe sobre o atendimento educacional especializado, e à Resolução no 4, de 02 de outubro de 2009, que institui diretrizes operacionais para o atendimento educacional especializado na educação básica, modalidade educação especial.

Além desses documentos, também trabalhamos com o exemplar Atendimento Educacional Especializado - Pessoa com Surdez $z^{4}$, juntamente com mais quatro exemplares $^{5}$ do material de subsídio para a formaçáo de professores para o atendimento educacional especializado (AEE) nos municípios-polo do Programa de Educação Inclusiva: Direito à Diversidade .

Ao olharmos para os documentos apresentados, buscamos, pela análise discursiva de inspiração pós-estruturalista ${ }^{7}$, analisar mecanismos de governamento postos em funcionamento pela atual racionalidade política. Como primeiro aspecto a ser discutido, visualizamos a identificaçáo dos espaços especiais de educação como espaços de segregação e de (a)normalidade, procurando-se convencer a população de que se educa melhor e de forma mais humana quando se educa na diversidade. Tal aspecto fica visível quando o documento Atendimento Especializado - Pessoa com Surdez, ao defender a inclusão, ressalta que

[...] a escola especial é segregadora, pois os alunos isolam-se cada vez mais, ao serem excluídos do convívio natural dos ouvintes. Há entraves nas relaçôes sociais, afetivas e de comunicação, fortalecendo cada vez mais os preconceitos. (BRASIL, 2007, p. 20)

Nesse sentido, entendemos que, na sociedade que se organiza a partir da ênfase neoliberal, não há mais espaços para instituições específicas de educação especial. A lógica da defesa da existência de lugares que abriguem a todos permite ao Estado maior governo pela economia de forças. $\mathrm{Na}$ continuidade da análise dos materiais, visualizamos, em diferentes momentos dos textos, a enfática defesa do envolvimento dos mais diferentes sujeitos que possam atuar no espaço escolar, visando à "plena" 
inclusão dos alunos, e do planejamento de serviços com vistas à provisão das necessidades dos alunos para que eles possam estar e permanecer na escola.

O AEE é, atualmente, a forma como os serviços da educação especial estão configurados dentro das escolas regulares para que estas tenham condições de atender os alunos em processo de inclusão. Na parceria entre escola regular e educação especial, são depositadas as crenças quanto ao êxito das propostas de educação inclusiva; tal serviço é referido como aquele que oferta "o conjunto de atividades, recursos de acessibilidade e pedagógicos organizados institucionalmente, prestado de forma complementar ou suplementar à formação dos alunos no ensino regular" (Decreto No 7.611). Para a previsão desse serviço, o professor responsável pelo AEE é chamado a responder por uma série de atividades, inclusive por aquelas direcionadas à orientação dos demais professores e das famílias dos alunos incluídos e a busca de parcerias com os demais serviços que se fizerem necessários.

Art. 13. São atribuiçóes do professor do Atendimento Educacional Especializado:

I - identificar, elaborar, produzir e organizar serviços, recursos pedagógicos, de acessibilidade e estratégias considerando as necessidades específicas dos alunos público-alvo da Educação Especial;

II - elaborar e executar plano de Atendimento Educacional Especializado, avaliando a funcionalidade e a aplicabilidade dos recursos pedagógicos e de acessibilidade;

III - organizar o tipo e o número de atendimentos aos alunos na sala de recursos multifuncionais;

IV - acompanhar a funcionalidade e a aplicabilidade dos recursos pedagógicos e de acessibilidade na sala de aula comum do ensino regular, bem como em outros ambientes da escola;

$\mathrm{V}$ - estabelecer parcerias com as áreas intersetoriais na elaboração de estratégias e na disponibilização de recursos de acessibilidade;

VI - orientar professores e famílias sobre os recursos pedagógicos e de acessibilidade utilizados pelo aluno;

VII - ensinar e usar a tecnologia assistiva de forma a ampliar habilidades funcionais dos alunos, promovendo autonomia e participação;

VIII - estabelecer articulação com os professores da sala de aula comum, visando à disponibilização dos serviços, dos recursos pedagógicos e de acessibilidade e das estratégias que promovem a participação dos alunos nas atividades escolares (BRASIL, 2009).

Como vimos, fica delegada ao professor do AEE grande parcela das açóes que esse serviço pressupóe. Que profissional será esse que dará conta de tantas funçóes e que, no desempenho de suas atividades, encontrará condiçôes de reverter situaçóes de in/exclusão que a própria escola vem produzindo? Parece-nos que esse será o profis- 
sional localizado nas escolas como aquele que deve responder pelos alunos incluídos, inclusive pelos sucessos e fracassos apresentados por esses alunos. Deverá estar atento às relaçôes familiares que esses alunos estabelecem, sendo capaz de orientar como pais e responsáveis devem comportar-se com relação a esses sujeitos para que deles se extraia o máximo de potencialidade possível. Deverá, ainda, promover interaçóes qualitativas entre esses alunos e seus professores para que momentos de aprendizagem formal sejam efetivados na escola.

Além do professor responsável pelo AEE, também há previsão de outros profissionais que, associados ao primeiro, são incumbidos de garantir a inclusão dos alunos com deficiência. Dessa forma, o Estado garante maiores possibilidades de sucesso ao seu projeto educacional e, o que nos parece ainda mais interessante, empenhando para isso esforços não vultosos, ou seja, com economia nas forças empregadas. Afinal, como vimos, "comprometer todos e cada um com o 'cuidado' necessário a esses indivíduos pode significar economia. Economia nos esforços que são empreendidos, que passam a ser diluídos na trama social" (MENEZES; RECH, 2009, p. 12).

Para além da centralidade do papel do professor do AEE na escola inclusiva, que acaba sujeitando professores a mobilizarem-se, cada vez mais, para prever, antecipar e estruturar condiçóes adequadas para a inclusão escolar e, principalmente, para o estabelecimento de parcerias com os demais sujeitos, temos ainda o planejamento de serviços com vistas à provisão das necessidades dos alunos para que possam estar e permanecer na escola.

Art. 10. O projeto pedagógico da escola de ensino regular deve institucionalizar a oferta do AEE prevendo na sua organização:

I - sala de recursos multifuncionais: espaço físico, mobiliário, materiais didáticos, recursos pedagógicos e de acessibilidade e equipamentos específicos;

II - matrícula no AEE de alunos matriculados no ensino regular da própria escola ou de outra escola;

III - cronograma de atendimento aos alunos;

IV - plano do AEE: identificação das necessidades educacionais específicas dos alunos, definição dos recursos necessários e das atividades a serem desenvolvidas (BRASIL, 2009).

Art. 3o Sáo objetivos do atendimento educacional especializado:

I - prover condições de acesso, participação e aprendizagem no ensino regular aos alunos;

II - garantir a transversalidade das açóes da educação especial no ensino regular;

III - fomentar o desenvolvimento de recursos didáticos e pedagógicos que eliminem as barreiras no processo de ensino e aprendizagem; e

IV - assegurar condiçóes para a continuidade de estudos nos demais níveis de ensino (BRASIL, 2011). 
Vê-se que a organização dos serviços do AEE passa pela institucionalização do serviço, a previsão de um espaço específico para o atendimento dos alunos, a elaboração de planos de ação para cada aluno em específico e a previsão de recursos que garantam o máximo possível de acesso dos alunos aos conhecimentos trabalhados em sala de aula, entre outras açôes. Com esses encaminhamentos, podemos ver a possibilidade de a educação especial agir na demarcação de seus espaços, de seus saberes, de seus alunos e, inclusive, de metodologias específicas para o seu trabalho.

Parece-nos, neste momento, que os mesmos discursos legais que convidaram a educação especial a reconfigurar-se para não mais ser caracterizada como uma área de saber à parte da educaçáo regular acabam novamente orientando a educaçáo especial a demarcar suas especificidades. Com outras roupagens, a educação inclusiva traz a educação especial para dentro da escola regular e a responsabiliza pela implementação, desenvolvimento e acompanhamento das açóes relativas à educação inclusiva. Há diferenças entre as práticas que antes eram desenvolvidas? Talvez a diferença resida no fato de que, uma vez que o aluno com deficiência esteja dentro da escola regular, múltiplas práticas de controle sobre ele podem ser postas em funcionamento e, como já dito anteriormente, quanto mais controle, maior economia nas forças que o governo precisa despender com os sujeitos.

Entendemos que assim se esvaziam de sentido os princípios tão proclamados pelos discursos inclusivos, que encontram na diminuiçáo dos preconceitos, no direito de igualdade de oportunidade e, especialmente, no respeito à diferença os argumentos para a abertura da escola para todos. Afinal, o fato de alunos com deficiência e sem deficiência compartilharem espaços em comum dentro da escola regular não garante respeito à diferença, ressignificação de preconceitos e desnaturalização de caridades e assistencialismos. Não garante, enfim, que os sujeitos sejam percebidos para além dos estigmas, dos rótulos de incapazes e de não- aprendizes.

Quando questionamos a defesa tão enfática do "respeito à diferença”, estamos nos referindo à concepção de diferença presente nos documentos analisados, que passa necessariamente pela identificação de atributos físicos e capacidades cognitivas de cada aluno. Uma vez identificados tais atributos e capacidades, os alunos poderão entâo ser classificados em grupos e encaminhados para o espaço de AEE mais indicado.

Art. $4^{\circ}$ Para fins destas Diretrizes, considera-se público-alvo do AEE:

I - Alunos com deficiência: aqueles que têm impedimentos de longo prazo de natureza física, intelectual, mental ou sensorial.

II - Alunos com transtornos globais do desenvolvimento: aqueles que apresentam um quadro de alteraçóes no desenvolvimento neuropsicomotor, comprometimento nas relações sociais, na comunicaçâo ou estereotipias motoras. Incluem-se nessa definição alunos com autismo clássico, síndrome de Asperger, síndrome de Rett, transtorno desintegrativo da infância (psicoses) e transtornos invasivos sem outra especificaçáo. 
III - Alunos com altas habilidades/superdotação: aqueles que apresentam um potencial elevado e grande envolvimento com as áreas do conhecimento humano, isoladas ou combinadas: intelectual, liderança, psicomotora, artes e criatividade. (BRASIL, 2009)

Ao defenderem a possibilidade de classificação e nomeação da diferença e a busca de práticas que a respeitem e a tolerem, as políticas educacionais possibilitam que visualizemos a concepção de diferença que permeia seus projetos, qual seja, aquela que parte da lógica da representação. Conforme Gallo (2009, p. 07),

A questáo é que estamos colonizados pela filosofia da representaçáo e, em seu contexto, percebemos a diferença em relação a esse e não em relação a si mesma. A lógica da representaçấo é centrada no princípio de identidade, que afirma que uma coisa é idêntica a si mesma. $(\mathrm{A}=\mathrm{A})$ e diferente de seu outro $(\mathrm{A}=\mathrm{B})$

Pensar a diferença a partir de um referencial e não a partir dela mesma significa pensá-la como uma "variação" do mesmo, uma variação da norma, que existe para ser cada vez mais confirmada, enfatizada. Quando estabelecemos que os alunos com deficiência devem constituir grupos específicos de aprendizagem, o fazemos mediante comparação entre aqueles que "aprendem" e os que "não aprendem" (ou que não aprendem da forma considerada adequada?), considerando que estes, para aprender, necessitam de suportes específicos. No contexto dos materiais analisados, a diferença surda é nomeada a partir da lógica da representação, e assim somos orientados a "entender o uso do termo pessoa com surdez como uma forma de nos reportarmos a pessoas com uma deficiência auditiva, independente do grau da sua perda sensorial" (BRASIL, 2007, p. 13).

$\mathrm{Na}$ continuidade das orientaçôes, depois de feitos os esclarecimentos necessários sobre qual a diferença que está sendo discutida, o material justifica a necessidade e a importância da inclusão para os sujeitos surdos:

\begin{abstract}
Estudos realizados na última década do século XX e início do século XXI por diversos autores e pesquisadores oferecem contribuiçóes à educaçáo de alunos com surdez na escola comum ressaltando a valorização das diferenças no convívio social e o reconhecimento do potencial de cada ser humano. (BRASIL, 2007, p. 13)
\end{abstract}

Respeitar a diferença surda e favorecer a inclusão do aluno surdo, nessa perspectiva, parece significar reduzir a inclusão de todos os alunos com surdez e/ou deficientes auditivos ao reconhecimento e à utilizaçâo da Língua Brasileira de Sinais (Libras). Parece-nos que há uma crença de que, pela garantia do direito à língua, se assegura o reconhecimento da diferença desses sujeitos. Nesse sentido, cabe ressaltar que, nos documentos, a Libras funciona com articuladora do processo de aprendizagem da Língua Portuguesa pelos alunos surdos. Queremos dizer com isso que, nas políticas que visam a incluir os surdos na escola comum, o ensino de Libras aparece como um aprendizado de reforço, e não como uma língua que constitui uma cultura, nesse caso, a cultura surda. 
Verificamos que a defesa da Libras como uma possibilidade de acesso à Língua Portuguesa vem funcionando como uma estratégia de normalização dos sujeitos surdos, uma vez que o foco da prática escolar não está no aprendizado de conteúdos, mas no acesso a eles por todos os indivíduos. Guedes (2009, p. 39) entende que se essencializa "a surdez com base na língua, ou seja, transforma-se a Libras em uma espécie de essência surda [...]", com a intenção de que todos sejam in/excluídos. Parece-nos que, na concepção que perpassa tal discussão, a língua é significada como uma espécie de segurança e de motivação aos surdos para que eles possam aprender e ser incluídos na sociedade.

Assim, diante das análises aqui empreendidas, podemos compreender que, em tempos de educação inclusiva, na busca de efetivação da escola que deve atender à diversidade, encontramos uma agenda política que produz cada vez mais novos e diferentes mecanismos de governamento para que todos possam estar e permanecer na escola. O foco é dirigido para a produção de sujeitos úteis aos princípios e objetivos neoliberais, mascarados por discursos de moralidade, de direitos humanos e de valorização da diversidade, para produzir o convencimento de todos a mobilizarem-se, juntos, para que a inclusão aconteça.

Se entendemos que nomear a diferença significa operar pela lógica da representaçáo, partindo de referências de normalidade, podemos entender que as políticas de inclusão, ao estabelecerem quem são os alunos que devem receber o atendimento educacional especializado, marcam as diferenças de alguns com relação a outros. Tomando a norma como princípio de comparabilidade, as diferenças dos alunos incluídos acabam sendo significadas como desvantagens e, assim, a partir do momento em que são localizadas, são também submetidas a práticas que, postas em funcionamento, buscam o seu apagamento. Tal análise leva-nos a pensar se a defesa da igualdade de oportunidades pode ser lida, então, como a defesa do apagamento das diferenças.

$\mathrm{Na}$ contramão dessa lógica, para concluir (e provocar), propomos que olhemos para a diferença como um conceito filosófico, entendendo que ela existe, ainda que não a respeitemos, não a toleremos, não a aceitemos. Ela existe, continuará existindo e será vivida e experienciada, independentemente de nosso desejo de percebê-la e dos espaços de convivência que venhamos a frequentar, sejam eles especiais ou regulares.

\section{Referências}

BRASIL. Ministério da Educação. Resolução no 4 de 2009. Brasília, DF, 2009.

BRASIL. Ministério da Educação. Decreto no 7.611 de 2011. Brasília, DF, 2008.

BRASIL. Ministério da Educação. Política Nacional da Educaçáo Especial na perspectiva da Educaçáo Inclusiva. Brasília, DF, 2008.

BRASIL. Atendimento Educacional Especializado - Pessoa com Surdez. Brasília, DF, 2007.

BRASIL. Lei no 9394/ 96. Lei de Diretrizes e Bases da Educação Nacional. Brasília, DF, 1996.

BRASIL. Lei no 4.024/61. Lei de Diretrizes e Bases da Educaçâo Nacional. Brasília, DF, 1961.

CARVALHO, R. A nova LDB e a Educaçáo Especial. $3^{a}$ ed. Rio de Janeiro: WVA: 2002.

GALLO, S. Uma apresentação: diferenças e educação; governamento e resistência. In: LOPES, M. C.; HATTGE, M. D.(Orgs). Inclusáo Escolar: conjunto de práticas que governam. Belo Horizonte: Autêntica, 2009. 
GUEDES, B. S.. A língua de Sinais na escola inclusiva: estratégias de normalizaçâo da comunidade surda. In: LOPES, M. C.; HATTGE, M. D. (Orgs). Inclusáo Escolar: conjunto de práticas que governam. Belo Horizonte: Autêntica, 2009.

MENEZES, E. da C. P. de; RECH, T. L. Práticas de subjetivação nos movimentos de integração e inclusão escolar. Anais do VI Congresso Internacional de Educação. UNISINOS: São Leopoldo, 2009.

ROSE, N. Governando a alma: a formaçấo do eu privado. In: SILVA, T. T. da (Org.). Liberdades reguladas. Petrópolis: Vozes, 1999.

SARAIVA, K. O Clube Penguin e o governo dos infantis. Disponível em: <http://www.cibersociedad.net/ congres2009/po/coms/o-club-penguin-e-o-governo-dos-infantis/1069>. Acesso em 16 de dezembro de 2011.

VEIGA-NETO, A. Neoliberalismo, Império e Políticas de Inclusão: problematizaçōes iniciais. In: RECHICO, C. F. \& FORTES, V. G. (Orgs). A educação e a inclusáo na contemporaneidade. Roraima: UFRR, 2008. p. $11-28$.

\section{Notas}

${ }^{1}$ Compreendemos governamento como a condução das condutas do outro, que se dá com o consentimento desse outro.

${ }^{2}$ Segundo dados disponíveis na Política Nacional da Educação Especial na perspectiva da Educação Inclusiva (2007), "entre 1998 e 2006, houve um crescimento de 640\% das matrículas em escolas comuns (inclusăo) e $28 \%$ nas escolas e classes especiais".

${ }^{3}$ Tal Decreto, ao ser aprovado, revoga o Decreto N. ${ }^{\circ} 6571$, de setembro de 2008.

${ }^{4} \mathrm{~A}$ eleiçăo do exemplar referente à área da surdez nesta análise deve-se ao fato de este estudo, juntamente com outros trabalhos, já concluídos ou em fase de construçâo, constituiu uma série de investigaçōes desenvolvidas pelo GIPES (do qual somos integrantes) cujo foco estava em conhecer as condiçôes de escolarizaçáo dos alunos surdos no Estado do Rio Grande do Sul.

${ }^{5}$ AEE - Deficiência Mental; AEE - Deficiência Física; AEE - Deficiência Visual e Orientaçóes Gerais e Educação a Distância. Disponíveis no site da Secretaria de Educação Continuada, Alfabetizaçăo, Diversidade e Inclusão do Ministério da Educação http://portal.mec.gov.br/index.php?option=com_content\&view=article\&id=290\&Itemid=816

${ }^{6}$ Implementado pelo MEC em 2003, o Programa Educação Inclusiva: Direito à Diversidade tem o objetivo de organizar e estruturar o processo de formação de gestores e educadores nos municípios brasileiros para a efetivação da escola inclusiva.

${ }^{7}$ Realizar uma análise do discurso na perspectiva pós-estruturalista significa trabalhar com o conceito de linguagem como constitutiva e produtora de realidades. Nessa perspectiva, entende-se que as formulaçóes discursivas - constituídas a partir de regras que podem ser alteradas, a depender de quem fala, em que contexto e com que intençóes fala - sempre acabaráo por determinar a realizaçáo de práticas que colocam um discurso em funcionamento, operando, portanto, para a produçấo de determinados efeitos desejados.

\section{Correspondência}

Eliana da Costa Pereira de Menezes - Universidade Federal de Santa Maria, Departamento de Educação Especial. Av. Roraima, n. 1000, Cidade Universitária - Camobi, CEP: 97105-900 - Santa Maria, Rio Grande do Sul - Brasil.

E-mail: elianacpm@hotmail.com - vanessascheid@hotmail.com

Recebido em 28 de abril de 2014

Aprovado em 06 de julho de 2014 